\title{
EVALUATION OF ROYAL JELLY AS AN ALTERNATIVE TO FETAL BOVINE SERUM IN CELL CULTURE USING CELL PROLIFERATION ASSAYS AND LIVE CELL IMAGING
}

\author{
Marahaini Musa ${ }^{1}$, Nurul Fatihah Mohamad Nasir ${ }^{1}, K$ annan Ponnuraj Thirumulu ${ }^{1,2^{*}}$
}

\author{
${ }^{1}$ School of Dental Sciences, Universiti Sains Malaysia, 16150 Kubang Kerian, Kelantan, Malaysia \\ ${ }^{2}$ Human Genome Centre, School of Medical Sciences, Universiti Sains Malaysia, 16150 Kubang Kerian, Kelantan, \\ Malaysia. \\ *E-mail: tpkannan@kb.usm.my
}

\begin{abstract}
Background: Royal jelly is a nutritious substance produced by the young nurse bees and contains significant amounts of proteins which are important for cell growth and proliferation. The aim of this study was to evaluate the effect of royal jelly as an alternative to fetal bovine serum (FBS) in cell culture using cell proliferation assays and live cell imaging.

Materials and Methods: MRC-5 cells were treated with various concentrations of royal jelly extract in MTT assay. The control groups were comprised of Alpha-Minimal Essential Medium ( $\alpha$-MEM) alone and $\alpha$-MEM with $10 \%$ FBS. Subsequently, the cell proliferation was studied for 10 days using Alamar Blue assay and live cell imaging from 48 to $72 \mathrm{~h}$. The population doubling time (PDT) was determined using trypan blue assay after live cell imaging.

Results: In MTT assay, 0.156 and $0.078 \mathrm{mg} / \mathrm{ml}$ of royal jelly produced higher cell viability compared to positive control group but were not significantly different $(P>0.05)$. In the Alamar Blue assay, 0.156 and $0.078 \mathrm{mg} / \mathrm{ml}$ of royal jelly produced greater percentage of reduction at day 3 even though no significant difference was found $(P>0.05)$. Based on live cell imaging, the PDT for positive, negative, 0.156 and $0.078 \mathrm{mg} / \mathrm{ml}$ of royal jelly groups were $29.09,62.50,41.67$ and $41.67 \mathrm{~h}$ respectively. No significant difference was found in the PDT between all the groups $(P$ $>0.05$ ).

Conclusion: Royal jelly does not exhibit similar ability like FBS to facilitate cell growth under the present test conditions.
\end{abstract}

Keywords: Royal jelly, proliferation, cell division, live cell imaging

\section{Introduction}

Among foods that possess the characteristic of functionality include all those that originated in beehive. Royal jelly is one of the consumable bee products besides honey and propolis (Viuda-Martos et al., 2008). Royal jelly is a substance of complex chemical structure produced by the young nurse bees and secreted from glands on the tops of their heads (Yatsunami et al., 1987). Royal jelly is produced exclusively for the nourishment of the queen bee for the whole life and for 2-3 days. Royal jelly is the only food given to all young larvae (Brouwers et al., 1987). Due to this condition, the queen bees develop superior characteristics of size, strength and longevity. The dramatic effects on the queen bee's growth and lifespan has led to many clinical studies to find out whether any of its properties can benefit human beings. Royal jelly contains remarkable amounts of proteins, lipids, glucides, vitamins, hormones, enzymes, and mineral substances (Howe et al., 1985). The composition of elements in the royal jelly are water (50\% to 60\%), proteins (18\%), carbohydrates (15\%), lipids (3\% to 6\%), mineral salts (1.5\%), and vitamins (trace amount) (Nagai and Inoue, 2004). A large number of bioactive substances such as 10-hydroxyl-2-decenoic acid (10H2DA) (Caparica-Santos and Marcucci, 2007) with immunomodulating properties (Ferlat et al., 1994), antibacterial protein, royalisin (Fujiwara et al., 1990; Eshraghi and Seifollahi, 2003), fatty acids (Vucevic et al., 2007), and peptides (Tokunaga et al., 2004) make up some of the components in royal jelly. It is reported that DIII protein contained in royal jelly can stimulate cell proliferation and seemed useful as a supplement to the serum free medium (Watanabe et al., 1998). Many scientific studies claimed that royal jelly has pharmacological properties such as antioxidant, neurotrophic, hypoglycemic, hypocholesterolemic, hepatoprotective, hypotensive and blood pressure regulatory, anti-tumour, antibiotic, antiinflammatory, immunomodulatory and anti-allergic, general tonic and anti-aging agent due to its complex composition (Mărghitaş, 2008). Though the use of royal jelly in many medical fields has been established as mentioned earlier, its role in cell culture has not been reported yet.

Based on the nutritional properties of royal jelly, it has the potential to replace the fetal bovine serum (FBS) that is widely used in cell culture media as a supplement. Cell or tissue culture routinely requires the application of animal-derived products or serum as components in culture medium. One particular example is FBS. FBS contains a mixture of biomolecules which promote cell growth and stimulate proliferation of cell. Because of its rich content of growth factors and its low gamma-globulin content, FBS has become the standard supplement of cell culture media. FBS is good for cell attachment, growth and proliferation in vitro (Gstraunthaler, 2003). FBS is obtained from bovine fetus via closed system of collection at the slaughterhouse. The usage of fetal bovine serum may involve both moral and scientific problems with the composition varying between batches and having a possibility of contamination with viruses, mycoplasma and prions (Eliot, 1999; Shah, 1999; Wessman and Levings, 1999; Gstraunthaler, 2003). Due to those issues regarding the application of FBS, an alternative to the animal serum is needed particularly for cell culture purpose. Royal jelly that has been known as a nutritious supplement and contains elements like proteins which are important for cell growth may potentially act as the substitute for FBS. Another bee product that has been studied to be used as supplement to FBS was Tualang honey (Kannan et al., 2009). It is essential for an alternative material to replace FBS to have similar constituents or components which enable cells to grow. Hence, the present study aims to evaluate royal jelly as an alternative to fetal bovine serum in cell culture using MTT assay, Alamar Blue assay and live cell imaging on human lung fibroblast cell line (MRC-5). 
http://dx.doi.org/10.4314/ajtcam.v11i1.23

\section{Materials and methods}

Royal jelly

The royal jelly used in the present study was from Acacia sp. tree, originally from Malaysia.

Cell line

Human fibroblast cell line (CCL-171) designated as MRC-5 was obtained from American Type Culture Collection (ATCC), USA.

\section{Reagents}

Reagents included the following: Alpha-Minimal Essential Medium ( $\alpha$-MEM) (IX) (GIBCO, USA), Penicillin (5000 units/ml) and Streptomycin $(5000 \mu \mathrm{g} / \mathrm{ml})$ antibiotic solutions (GIBCO, New Zealand), FBS (GIBCO, New Zealand), trypsin-EDTA (0.25\%) solution (GIBCO, New Zealand), phosphate buffered saline IX (PBS) (GIBCO, New Zealand), trypan blue dye (0.4\%) (Invitrogen, USA), CellLight ${ }^{\mathrm{TM}}$ NucleusGFP and CellLight ${ }^{\mathrm{TM}}$ Mitochondria-RFP (BacMam 2.0) fluorescent expression systems (Life technologies, USA).

\section{Royal jelly extraction}

Royal jelly $(0.5 \mathrm{~g})$ was weighed and put into $1.5 \mathrm{ml}$ sterile centrifuge tube. The sample was then sterilised by exposing it to $25 \mathrm{kGy}$ of gamma $(\gamma)$ radiation. Extract of royal jelly was prepared by diluting the royal jelly in culture medium $(\alpha-M E M)$ without addition of FBS, supplemented with $1 \%$ of penicillin-streptomycin antibiotic mixture. The concentration of stock prepared was $5 \mathrm{mg} / \mathrm{ml}$, which was stored at $4^{\circ} \mathrm{C}$ until use. For the testing, royal jelly stock was diluted into desired concentrations using culture medium, $\alpha$-MEM which was prepared as mentioned earlier.

\section{Cell culture}

MRC-5 cells were grown in $\alpha$-MEM with L-Glutamine and without ribonucleoside and deoxyribonucleosides, supplemented with $10 \%$ FBS and $1 \%$ of penicillin-streptomycin antibiotic mixture. The cells were maintained at $37^{\circ} \mathrm{C}$ in a humidified incubator supplemented with $5 \%$ $\mathrm{CO}_{2}$.

\section{Cytotoxicity test}

Cytotoxicity of royal jelly on MRC-5 cell line was studied using 3-(4,5-dimethylthiazol-2-yl)-2,5-diphenyltetrazolium bromide (MTT) assay which was developed by Mosmann (1983). Confluent MRC-5 cells were washed with PBS and trypsinized using trypsin-EDTA solution. Cells were then centrifuged at $1200 \mathrm{rpm}$ for $5 \mathrm{~min}$ and the cell pellet was re-suspended in the medium. Ten microlitre of cell suspension was mixed with $10 \mu \mathrm{l}$ of $0.4 \%$ trypan blue solution and the number of viable cells were counted using haemocytometer. MRC-5 cells $\left(1 \mathrm{x} 10^{4}\right)$ were seeded onto triplicate 96 -well plate and treated with different concentrations of royal jelly extract $(2.5,1.25,0.625,0.313,0.156$ and 0.078 $\mathrm{mg} / \mathrm{ml}$ ) for 72 hours. Two controls were included in the test. For negative control wells, only $\alpha$-MEM and cell suspension were added, while cell suspension together with $\alpha$-MEM and $10 \%$ FBS were added into the positive control group wells. Penicillin-streptomycin at the rate of $1 \%$ was added into both culture media. Ten microlitre of $0.5 \mathrm{mg} / \mathrm{ml}$ MTT solution which was diluted with PBS was added into all wells following the incubation period. The cells were incubated further for 4 hours at $37^{\circ} \mathrm{C}$ and then the medium was removed. Formazan crystals formed in wells were dissolved by adding $100 \mu \mathrm{l}$ of DMSO into each well. Absorbance of each group was read at $570 \mathrm{~nm}$ using ELISA plate reader (Tecan, Switzerland). The relative viability of the cells compared to the control was determined using the following formula:

$\%$ Cell Viability $=\left[\mathrm{A}_{570}\right.$ of treated cells $] \times 100 \% /\left[\mathrm{A}_{570}\right.$ of control cells $]$

Concentration of royal jelly which produced cell viability greater than positive control ( $\alpha$-MEM $+10 \%$ FBS) was used for the cell proliferation assay. From MTT assay result, dose inhibition graph was constructed. The morphology of cells incubated with royal jelly extract also was observed at the end of the incubation period (72 hours).

\section{Cell proliferation assay (Alamar Blue assay)}

Standard curve for MRC-5 cells was constructed prior to treatment with royal jelly where different numbers of MRC-5 cells (50000, $25000,12500,6250,3125,1563,781,391$ cells) were incubated for 24 hours before Alamar Blue dye was added. For Alamar Blue assay, 2 x $10^{3}$ of cells were seeded in 96-well plate and treated with concentrations of royal jelly from MTT assay result, concurrently with positive $(\alpha-M E M+$ $10 \%$ FBS) and negative control ( $\alpha$-MEM only) for 24 hours. All culture medium was supplemented with $1 \%$ penicillin-streptomycin. After incubation period, $10 \mu \mathrm{l}$ of Alamar Blue dye was added and the plate was further incubated for 4 hours. Then, the medium was aspirated into another 96-well plate and the absorbance of each well was read at 570 and $600 \mathrm{~nm}$ using ELISA plate reader. Alamar Blue assay was conducted over a period of 10 days and carried out in triplicates. Percentage of reduction (\% reduction) of Alamar Blue for all groups was calculated using the formula derived by Willard et al. (1965) as given below:

$\%$ reduction $=\left[(117.216) \mathrm{A}_{570^{-}}(80.586) \mathrm{A}_{600}\right] /\left[(155.677) \mathrm{A}^{\prime}{ }_{600^{-}}(14.652) \mathrm{A}^{\prime}{ }_{570}\right] \times 100 \%$

Where 117.216: molar extinction coefficient of Alamar Blue in the oxidized form at $600 \mathrm{~nm}$; 80.586: molar extinction coefficient of Alamar Blue in the oxidized form at $570 \mathrm{~nm}$; 14.652: molar extinction coefficient of Alamar Blue in the reduced form at $600 \mathrm{~nm}$; 155.677: molar extinction coefficient of Alamar Blue in the reduced form at $570 \mathrm{~nm} ; \mathrm{A}_{600}$ : absorbance of test wells at $600 \mathrm{~nm} ; \mathrm{A}_{570}$ : absorbance of test wells at $570 \mathrm{~nm}$; $\mathrm{A}_{600}^{\prime}$ : absorbance of negative control wells at $600 \mathrm{~nm} ; \mathrm{A}_{570}^{\prime}$ : absorbance of negative control wells at $570 \mathrm{~nm}$. growth.

Graph of percentage of reduction of all groups over time was constructed. Greater percentage of reduction represented higher level cell 
MRC-5 cells were seeded in four-compartments, $35 \mathrm{~mm}$ tissue culture dish at a cell density of $3 \times 10^{3}$ cells. The cells were incubated either with concentrations of royal jelly from MTT assay result, positive control ( $\alpha$-MEM with $10 \%$ of FBS) or negative control ( $\alpha$-MEM only). The experiments were conducted in triplicates. After overnight incubation, 0.6 $\mu \mathrm{L}$ of CellLight ${ }^{\mathrm{TM}}$ Nucleus-GFP (BacMam 2.0) and CellLight $^{\mathrm{TM}}$ Mitochondria-RFP (BacMam 2.0) fluorescent expression system was then added into each compartment of tissue culture dish. The cells were then incubated at $37^{\circ} \mathrm{C}$ in a humidified incubator supplemented with $5 \% \mathrm{CO}_{2}$ for at least 16 hours. Prior to the live cell imaging test, the medium was changed and PBS was used to wash the cells. New culture medium and royal jelly extract without addition of fluorescent expression system were added into the wells. The cells were subjected to live cell imaging at 48 to 72 hours after cell seeding. Images of cells were captured every half hour for 24 hours by using live cell imaging system (Vivatome, Zeiss, Germany) and analysed using Axio Vision Rel. 4.8 software (Zeiss, Germany) where a video was produced over the period of incubation. Cell division process was observed and any changes in cell morphology were noted.

As the live cell imaging is a qualitative analysis, trypan blue assay was performed to quantify the number of viable cells in all groups. Following the incubation for live cell imaging ( 72 hours after cell seeding), the cells were washed, trypsinized and counted as mentioned earlier in the MTT assay section. The cell number was noted for the determination of population doubling time (PDT). PDT refers to the time it would take a population to double, assuming there is a constant growth rate (Teisch and De Sherbinin, 1995). PDT was measured using the following formula (Mather and Roberts, 1998):

$\mathrm{PDT}=1 / \mathrm{r}$

Where, multiplication rate $(r): 3.32\left(\log \mathrm{NH}-\log \mathrm{N}_{1}\right) /\left(t_{2}-t_{1}\right)$; N1: cell number at 0 hour $\left(3 \times 10^{3}\right.$ cells $)$; NH: cell number at 72 hours

\section{Statistical analysis}

Results of MTT assay, Alamar Blue test and live cell imaging between treatment groups were analysed using independent t-test using PASW statistical software package, version 18.0.1 (SPSS Inc., USA) for Windows. Differences were considered statistically significant when the $P$-value was $<0.05$.

\section{Results \\ Cytotoxicity test (MTT assay)}

For cytotoxicity evaluation of royal jelly on MRC-5 cells, different concentrations of royal jelly extract $(2.5,1.25,0.625,0.313,0.156$ and $0.078 \mathrm{mg} / \mathrm{ml}$ ) produced $71.46 \%, 77.29 \%, 86.30 \%, 83.02 \%, 89.94 \%$ and $90.67 \%$ of cell viability respectively. Cells treated with $\alpha-\mathrm{MEM}+$ $10 \%$ FBS produced $87.52 \%$ of viability. The relative viability of the cells compared to the control is shown in Figure 1.

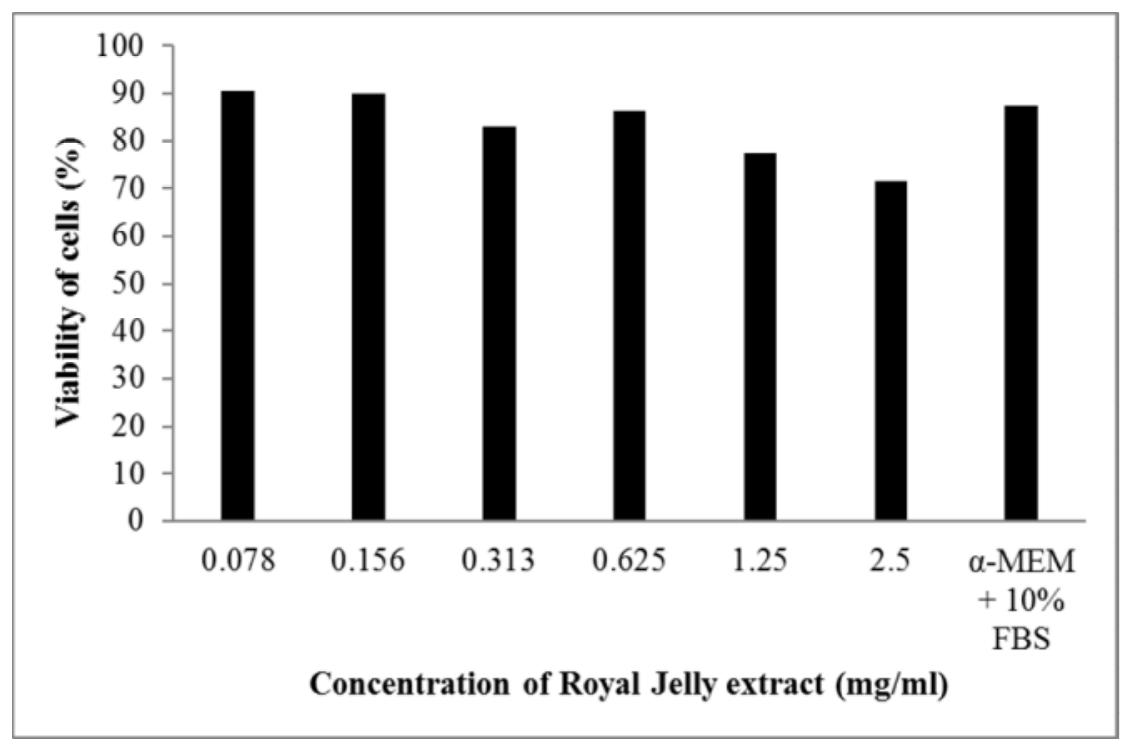

Figure 1: MTT assay of royal jelly on human lung fibroblast cell line (MRC-5)

Concentrations of royal jelly which produced cell viability higher than positive control ( $\alpha$-MEM $+10 \%$ FBS) were used for cell proliferation assay. Two concentrations of the royal jelly extract $(0.156$ and $0.078 \mathrm{mg} / \mathrm{ml})$ were selected for further tests. No significant difference in viability of cells was found between $\alpha$-MEM $+10 \%$ FBS and both royal jelly $(0.156$ and $0.078 \mathrm{mg} / \mathrm{ml})$ groups $(P>0.05)$. The morphology of cells treated with 0.156 and $0.078 \mathrm{mg} / \mathrm{ml}$ of royal jelly for 72 hours also were compared with that of the positive control. Royal jelly did not exhibit cytotoxic effect on MRC-5 cells where both concentrations $(0.156$ and $0.078 \mathrm{mg} / \mathrm{ml}$ royal jelly) showed almost similar cellular morphology with $\alpha$-MEM $+10 \%$ FBS group (Figure 2). 
http://dx.doi.org/10.4314/ajtcam.v11i1.23

Cell proliferation assay (Alamar Blue assay)

From Alamar Blue assay, standard curve for MRC-5 cells was constructed to investigate the growth pattern of the cell lines. In Figure 3, the cell number of MRC-5 cell line was proportional to percentage of reduction where higher cell count produced greater Alamar Blue dye reduction.
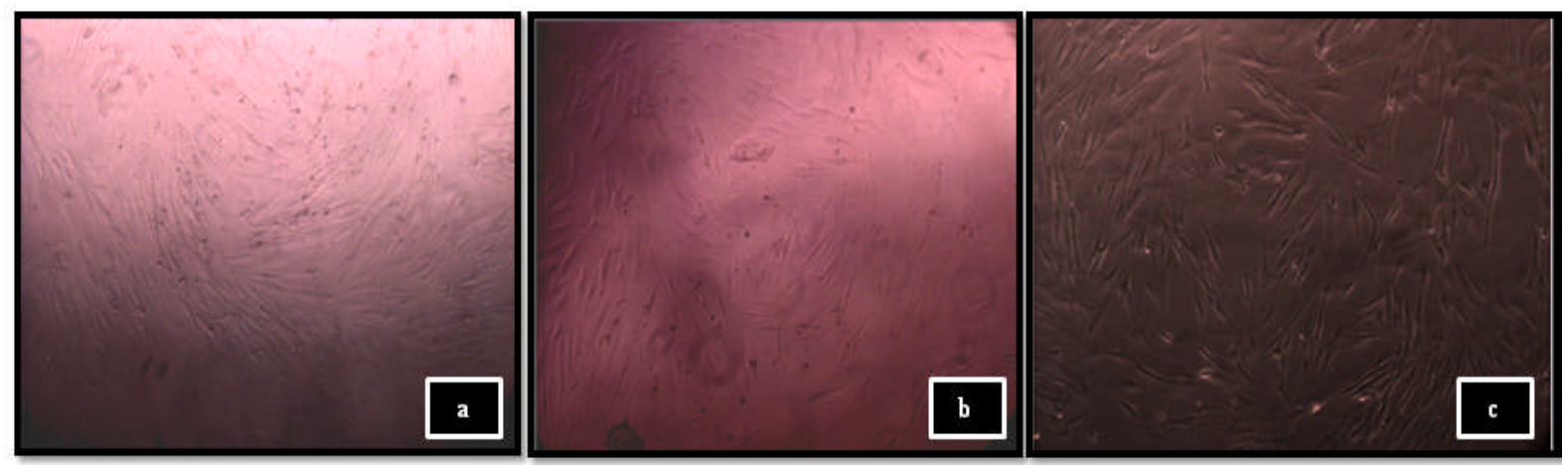

Figure 2: Cellular morphology of MRC-5 cells treated with (a) $0.156 \mathrm{mg} / \mathrm{ml}$ royal jelly; (b) $0.078 \mathrm{mg} / \mathrm{ml}$ royal jelly, and (c) Positive control ( $\alpha$ $\mathrm{MEM}+10 \%$ FBS)

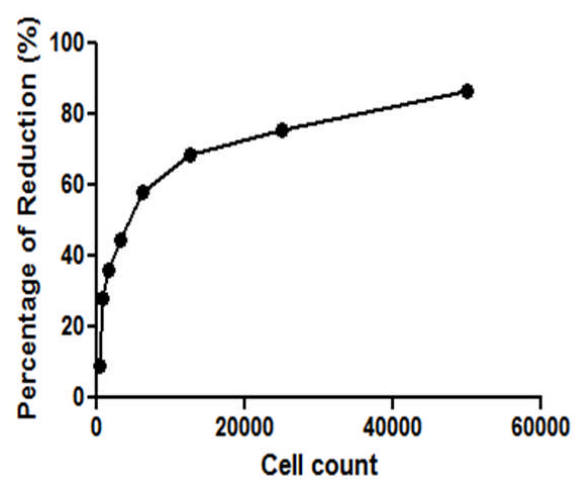

Figure 3: Standard curve of MRC-5 cells for Alamar Blue assay

Effect of royal jelly on cell proliferation studied using Alamar Blue assay was shown in Fig 4. On Day 1, there was difference in the value of percentage of reduction between all groups. Statistically, $0.078 \mathrm{mg} / \mathrm{ml}$ royal jelly produced no significant difference in percentage of Alamar Blue reduction compared to positive control $(P>0.05)$. However, there was significant percentage of reduction between positive and negative controls $(P<0.05)$. Throughout the experiment, 0.156 and $0.078 \mathrm{mg} / \mathrm{ml}$ royal jelly groups produced decreasing percentage of reduction, unlike the positive control where the value increased over time.

From Day 1 to Day 7, both groups treated with royal jelly extract produced higher percentage of reduction than negative control. On the third day of experiment, both 0.156 and $0.078 \mathrm{mg} / \mathrm{ml}$ royal jelly produced higher percentage of reduction compared to positive and negative controls even though no significant difference was found between all groups $(P>0.05)$. At Day 7 , percentage of reduction in royal jelly treatment groups differed significantly with positive groups $(P<0.05)$. On the final day of the experiment (Day 10), it was found that the percentage of reduction of 0.156 and $0.078 \mathrm{mg} / \mathrm{ml}$ royal jelly groups was significantly different from that of the positive control $(P<0.05)$, though not significantly different from the negative control $(P>0.05)$.

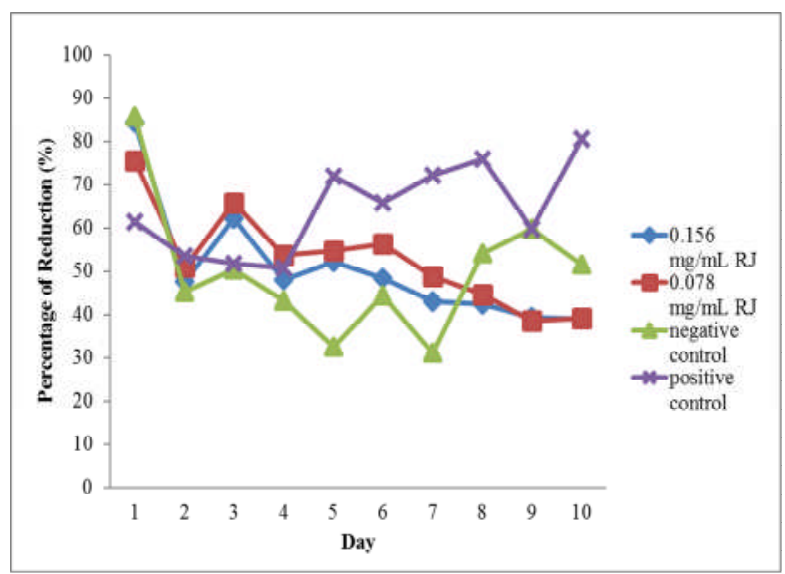

Figure 4: Results of Alamar Blue test on MRC-5 cells treated with 0.156 and $0.078 \mathrm{mg} / \mathrm{ml}$ of royal jelly (RJ), positive and negative control 


\section{Live cell imaging}

For live cell imaging, a video was produced from the images captured every 30 minutes for the duration of 24 hours of the experiment. Fig 5 shows the representative images of each treatment groups at the early (48 hours) and end ( 72 hours) of the study. As a surface adherent type of cell, MRC-5 cells in healthy state appear to have elongated, fibrous shape. As the cell begins to divide, it undergoes morphological changes. Cell division process started when there was change in the fibrous shape of the MRC- 5 cells. At the initial stage of cell division, the cells became round over time. The nucleus then was split into two which indicated the nuclear division process. Lastly, the cytoplasm divided and in the end produced two daughter cells from a mother cell through cytokinesis. The cells then separated from each other. After few hours, the cells became elongated, representing the further stage in cell attachment (Figure 6). The duration for a cell division process to be completed was $7 \pm 3$ hours based on the observation in live cell imaging.

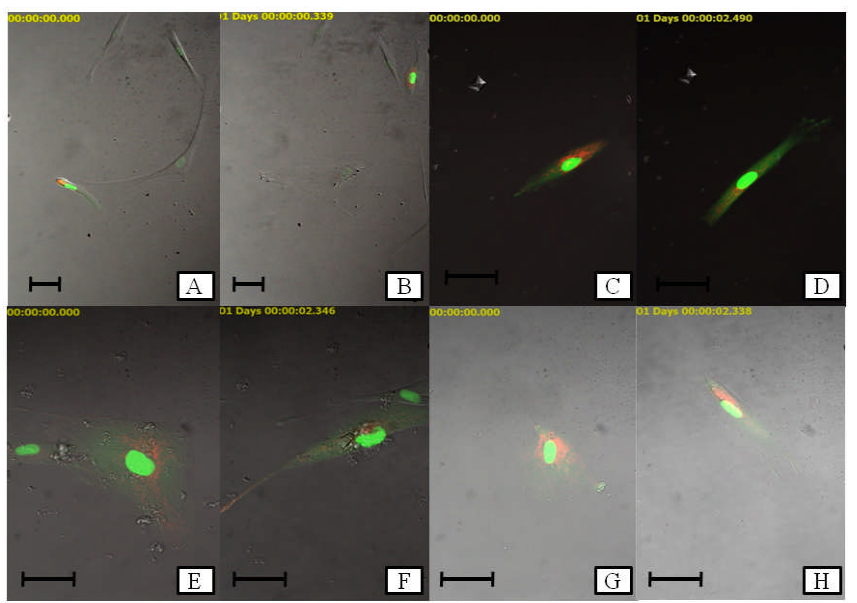

Figure 5: Representative images of MRC-5 cells treated with royal jelly through live cell imaging. a negative control ( 0 h); b negative control ( 24 $\mathrm{h})$; c positive control $(0 \mathrm{~h})$; d positive control $(24 \mathrm{~h})$; e $0.156 \mathrm{mg} / \mathrm{ml}$ of royal jelly $(0 \mathrm{~h})$; $\mathrm{f} 0.156 \mathrm{mg} / \mathrm{ml}$ of royal jelly $(24 \mathrm{~h})$; $\mathrm{g} 0.078 \mathrm{mg} / \mathrm{ml}$ of royal jelly $(0 \mathrm{~h})$ and $\mathrm{h} 0.078 \mathrm{mg} / \mathrm{ml}$ of roval iellv $(24 \mathrm{~h})($ Scale bar: $50 \mathrm{um})$
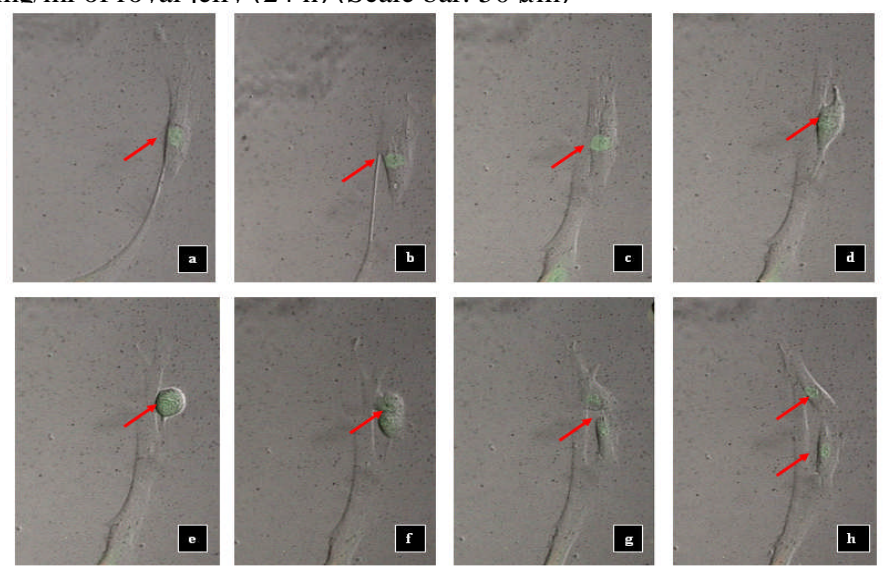

Figure 6: Cell division process of MRC-5 cells (negative control). a After $7.30 \mathrm{~h}$ (single cell); b After $10.30 \mathrm{~h}$; c After $12.30 \mathrm{~h}$; d After $13.00 \mathrm{~h}$; e After $13.30 \mathrm{~h}$; f After $14.00 \mathrm{~h}$; g After $14.30 \mathrm{~h}$ and $\mathrm{h}$ After $15.00 \mathrm{~h}$ (two daughter cells). Arrow denotes the individual cells.

For the determination of the PDT, numbers of cells at the end of the experiment were counted. Table 1 shows the PDT of all treatment groups. Positive control $(\alpha-\mathrm{MEM}+10 \%$ FBS $)$ produced the lowest PDT compared to royal jelly groups and negative control. PDT for negative control ( $\alpha$-MEM without addition of FBS) was the highest, suggesting slower cell proliferation compared to other groups. Even though there are differences in the mean PDT values, no statistical difference in PDT was found between groups $(P>0.05)$.

Table 1: Mean PDT of treatment groups

\begin{tabular}{|c|c|}
\hline Treatment group & PDT (Hours) ${ }^{\mathrm{c}}$ \\
\hline Positive control $^{\mathrm{a}}$ & 29.09 \\
\hline Negative control $^{\mathrm{b}}$ & 62.50 \\
\hline $0.156 \mathrm{mg} / \mathrm{ml} \mathrm{RJ}$ & 41.67 \\
\hline $0.078 \mathrm{mg} / \mathrm{ml} \mathrm{RJ}$ & 41.67 \\
\hline
\end{tabular}

\footnotetext{
${ }^{\mathrm{a}} \alpha-\mathrm{MEM}+10 \%$ FBS, ${ }^{\mathrm{b}} \alpha-\mathrm{MEM},{ }^{\mathrm{c}}$ Mean PDT of the three independent tests
} 
http://dx.doi.org/10.4314/ajtcam.v11i1.23

\section{Discussion \\ MTT assay}

MTT assay is a sensitive, quantitative and reliable colorimetric assay which measures viability, proliferation and activation of cells. The assay is based on the ability of the cellular mitochondrial dehydrogenase enzyme in living or viable cells to reduce the yellow water-soluble substrate 3-(4,5-dimethylthiazol-2yl)-2,5-diphenyl tetrazolium bromide into a dark blue/purple formazan product which is insoluble in water. The quantity of formazan produced is directly proportional to the number of cells (Mosmann, 1983; Gerlier and Thomasset, 1986).

In MTT assay, analysis of different concentrations of royal jelly on cell viability revealed that the viability of cells was not proportional to the concentrations of royal jelly. Dose dependent relationship was observed where the viability of cells decreased with increase in concentrations of royal jelly. Cells treated in less diluted royal jelly extract produced lower percentage of viability (Figure 1$)$ as more acidic $\mathrm{pH}$ of higher concentration of royal jelly will inhibit the growth and viability of cells. $\mathrm{pH}$ of fresh royal jelly is found to be low and in acidic range ( $\mathrm{pH}$ of 3.4-4.5) (Sabatini et al., 2009). Lower concentration of royal jelly might serve a more suitable pH for the cells to grow and proliferate compared to higher concentrations of the extract. As two concentrations of royal jelly extract $(0.156$ and $0.078 \mathrm{mg} / \mathrm{ml})$ produced greater cell viability compared to $\alpha$-MEM supplemented with $10 \% \mathrm{FBS}$, it shows the potential of royal jelly at these concentrations to exhibit similar ability like FBS. Hence, this data supports the results of earlier studies where royal jelly proteins were reported to stimulate the proliferation of U-937 monocytic human cells (Watanabe et al., 1998) and hepatocyte DNA synthesis and albumin production (Kamakura et al., 2001). This occurs through activation of several important intracellular signalling factors which is involved in stimulation of synthesis of hepatocyte DNA. 57-kDa protein in royal jelly is also involved in the protection of cells from apoptosis (Kamakura, 2002). Salazar-Olivo and Paz-González in 2005 also suggested that royal jelly contains growth factors or hormones promoting cell growth.

\section{Alamar Blue assay}

Alamar Blue $(\mathrm{AB})$ is a tetrazolium-based dye which incorporates resazurin and resorufin as oxidation-reduction indicators that yield colorimetric changes and a fluorescent signal in response to metabolic activity. The blue non-fluorescent colour in oxidised form becomes pink and fluorescent upon reduction (DeBaun and de Stevens, 1951; Page et al., 1993). As the concentration of viable cells increased, greater percentage of reduction is produced (Byth et al., 2001) which is translated as a sigmoid curve of standard (reference) graph. This has also been observed in the current study (Fig 3). Higher percentage of Alamar Blue reduction in MRC-5 cells was seen in the viable cell count <20000. This was supported by previous research which stated the reduction of Alamar Blue as detected by fluorescence that increased proportionally with fibroblast cell number over the range of 100 to 20000 cells (Voytik-Harbin et al., 1998). In the present study, the detection of dye reduction was performed using absorbance. Another method to quantify the Alamar Blue reduction is using fluorescence. Both absorbance and fluorescence methods offered excellent sensitivity and reproducibility (Voytik-Harbin et al., 1998).

The proliferation activity of the cells indicates the occurrence of cell division process. Proliferating cells have to replicate the entirety of their cellular contents in order to divide (Lemons et al., 2010). Based on the results of Alamar Blue assay (Fig 4), both royal jelly groups produced decreased percentage of reduction over time starting from day 3 onwards and a plateau could be observed at the middle stage of the experiment (days 4, 5 and 6). A plateau in dye reduction was produced with high cell densities and/or extended incubation times for the percentage of reduction, followed by a decline in absorbance or fluorescence. This has been noted by the manufacturer and has also been described for mammalian cells (Larson et al., 1997; Voytik-Harbin et al., 1998). This might explain the pattern in dye reduction seen in royal jelly groups. In positive controls, the percentage of Alamar Blue reduction increased over time, showing the proliferative activity of MRC-5 cells in $\alpha$ MEM $+10 \%$ FBS. From the Alamar Blue test results, even though there are differences in royal jelly and positive control group, it was hard to draw a conclusion on the proliferative rate of the treated cells as plateau and reduction in absorbance reading of royal jelly might be a result of active proliferative effect.

\section{Live cell imaging}

Live cell imaging as a new method in imaging has served as a valuable method to analyse the cellular activity. The recent improvements in imaging technology were contributed by the advancements in photochemistry/photobiology where development of sophisticated molecular probes which allowed the visualisation of discrete molecules within living cells (Lippincott-Schwartz et al., 2001; Rieder and Khodjakov, 2003). A major development in the field of bioimaging was the discovery of green fluorescent protein (GFP) (reviewed in LippincottSchwartz and Patterson, 2003) which allows the visualisation and imaging of individual protein. Chimeras made from any gene of interest coupled with GFP and with genetically engineered chromatic variations of GFP can be easily introduced into the cultured cells and genetically tractable organisms (Haraguchi, 2002; Zhang et al., 2002). The nature in which these GFP fusions retain their native biological activity while being fluorescently tagged made it a powerful tool for the investigation of dynamics of individual proteins at single cell level (Hinchcliffe, 2005).

The application expression of fluorescent proteins such as GFP in live cell imaging enables the detailed study of cell division in living cells (Rusan et al., 2001; Wang, 2001; Wadsworth and Khodjakov, 2004). The analysis of division of cell in fixed cells presented limitations to the researchers as many key events during mitosis occur only transiently. Dramatic changes in morphology of the spindle over the period of an hour or less and the significance of these events are often lost in fixed time-point samples. Continuous imaging, as in live cell imaging, acted as a solution to these problems. Video microscopy also provides the ability to determine the duration of an event and to examine the dynamic redistribution of the structural and regulatory proteins (Hinchcliffe, 2005).

In the present study, the expression of GFP and red fluorescence protein (RFP) of cells using live cell imaging was analysed using CellLight ${ }^{\circledR}$ (BacMan 2.0) fluorescence expression system. Fluorescence proteins (FPs) targeted to cell organelles by specific protein localisation signals enable visualisation of their morphology, fusion and fission, and also segregation during cell division. FPs act as an essential tool for individual cell labelling and tissue labelling to visualise morphology, location, and movement, mitotic stages, and many other important cell characteristics (Chudakov et al., 2010). CellLight ${ }^{\circledR}$ reagents are fluorescent protein-signal peptide fusions for live-cell imaging purpose. Cellular labelling utilises BacMam technology, which uses an insect cell virus (baculovirus) coupled with a mammalian promoter and involves transfection of human cells (Fornwald et al., 2007) to generate a stable line constitutively expressing nucleus-GFP and mitochondria-RFP without affecting the cell cycle progression, as in the present study. As seen in the current study, the expression of nucleus-GFP and mitochondria-RFP in MRC-5 resulted in green fluorescent colour of the nucleus and red fluorescent colour of the mitochondria. In this study, we investigated the 


\section{http://dx.doi.org/10.4314/ajtcam.v11i1.23}

proliferation effect of MRC-5 cells treated with either royal jelly extract $(0.156$ and $0.078 \mathrm{mg} / \mathrm{ml})$, positive and negative control via live cell imaging method with the aim of observing the cell division of MRC-5 cells treated with royal jelly. Two different concentrations of royal jelly were selected based on the previous test (MTT assay) in which 0.156 and $0.078 \mathrm{mg} / \mathrm{ml}$ royal jelly produced proliferation rate comparable with positive control $(\alpha-$ MEM $+10 \%$ FBS). Live cell imaging was performed from 48 to 72 hours after seeding based on the Alamar Blue assay results, where both royal jelly groups produced higher percentage of reduction compared to positive and negative controls from Day 2 to 3 .

Proliferative capacity which contributes to cells' lifespan in vitro has been reported to vary significantly with lots of serum (Schneider et al., 1978). The reduction in the concentration of serum resulted in the reduced MRC-5 cells' growth and attachment (Wistrom and Villeponteau, 1990). A study by Burgener et al. (2002) reported the duration for cell division of MRC-5 cells of 34.0 hours in serumsupplemented (5\% FBS) Dulbecco Modified Essential Medium (DMEM) medium for cell count of up to maximum density of cells of $1 \times 10^{6}$ cells/ $\mathrm{ml}$. The difference in the concentration of serum proved to be an essential factor in determining the time needed for cell division as for the MRC-5 cells cultured in DMEM medium with $10 \%$ of FBS resulted in much lower doubling time (approximately 24 hours) which indicated more active proliferation activity (Strait et al., 2005). However, in the present study, the PDT of cells treated in complete medium $(\alpha-M E M+10 \%$ FBS) is 29.09 hours, higher than time duration as reported earlier. This may be due to the use of different culture medium in the current study which was $\alpha$-MEM and not DMEM. The calculated PDT values also differed from the duration for completion of a cell division process $(7 \pm 3$ hours) observed in live cell imaging video as the division of cells seen in live cell imaging only indicated the mitosis stage of the cell cycle, not involving the other stages in cell cycle. Cell cycle can be divided into 4 stages; $\mathrm{G}_{1}, \mathrm{~S}, \mathrm{G}_{2}$ and $\mathrm{M}$. Morphologically, the cell cycle is classified into interphase $\left(\mathrm{G}_{1}, \mathrm{~S}, \mathrm{G}_{2}\right)$ and stages of $\mathrm{M}$ (mitosis), which include prophase, metaphase, anaphase and telophase (Alberts et al., 1983). However, as the determination of each stage of cell cycle was not performed during live cell imaging, it was impossible for the analysis of the exact time for the starting of the different phases of cell cycle in the cell division. Both royal jelly groups produced same PDT which suggests similarity in the proliferation rate of cells treated with 0.156 and $0.078 \mathrm{mg} / \mathrm{ml}$ of royal jelly. Based on the live cell imaging, there were differences in the appearance between the culture medium and royal jelly extract groups as insoluble royal jelly which floated in the extract of royal jelly was noticed (Fig 5). This insolubility property of royal jelly was supported by Bogdanov (2011) where royal jelly was found to be only partially soluble in water at a density of $1.1 \mathrm{~g} / \mathrm{ml}$. Though insoluble royal jelly can be removed from the medium by using the filter, this was not applied in this study as the process of filtration might eliminate the components present in the royal jelly, thus changing its properties. Some limitations were observed in this study. As only a field was subjected to live cell imaging, there was a possibility of error occurring during the test. From the live video of each treatment groups including positive and negative control, it was noticed that the cells moved as the cell division took place. Due to this action, some cells were out of the focussed field throughout the 24 hours of incubation, resulting in an inadequate analysis of the cell's division and its changes in the morphology. The PDT determination also was done by trypan blue assay after the live cell imaging as there was inaccurate reading based on the counting of cells at the start (48 hours) and end ( 72 hours) directly from the live cell imaging image due to the problem mentioned earlier. As only a fixed field was used in the live cell imaging and there were movement of cells into/out of the field, it was not possible to determine the exact number of cells in the treatment groups.

\section{Conclusion}

Based on the results from MTT assay, Alamar Blue assay and live cell imaging, although royal jelly has the potential to be used as an alternative to FBS in cell culture, it does not exhibit similar ability like FBS to facilitate cell growth and proliferation under the present test conditions.

Conflict of interest statement: None declared.

\section{Acknowledgements}

The authors would like to acknowledge Professor Dr. Siti Amrah Sulaiman, Department of Pharmacology, School of Medical Sciences, Mss. Shahida Nabila Serat, Nur Afizah Yahaya and Tan Shu Xhin and the staff of Craniofacial Sciences Laboratory, School of Dental Sciences, Universiti Sains Malaysia (USM), and the USM Short Term Grant (304/PPSG/61312032).

\section{References}

1. Alberts, B., Bray, D., Lewis, J., Raff, M., Roberts, K and Watson, J. D. (1983). Molecular Biology of the Cell. New York, US, Garland.

2. Bogdanov, S. (2011) Royal jelly, bee brood: composition, health, medicine: A re-view. Bee. Product. Sci.: 1-31.

3. Brouwers, E., Ebert, R and Beetsma, J. J. (1987). Behavioural and physiological aspects of nurse bees in relation to the composition of larval food during caste differentiation in the honeybee. Apic. Res., 26: 11-23.

4. Burgener, A., Patrick, M., Coombs, K., Moffatt, D., Huzel, N and Butler, M. (2002). The Modification of a Serum-Free Media Formulation for the Production of Reovirus and the Growth of Vero, MRC-5, MDCK and BHK Cell Lines. In (E. Lindner-Olsson, N. Chatzissavidou and E. Lüllau eds) Animal Cell Technology: From Target to Market. Netherlands, Springer, pp. 200-203.

5. Byth, H-A., McHunu, B. I., Dubery, I. A and Bornman, L. (2001). Assessment of a simple, non-toxic Alamar blue cell survival assay to monitor tomato cell viability. Phytochem. Analysis., 12: 340-346.

6. Caparica-Santos, C and Marcucci, M. C. J. (2007). Quantitative determination of trans-10-Hydroxy-2-Decenoic Acid (10-HDA) in Brazilian royal jelly and commercial products containing royal jelly. Apicult. Res., 46: 149-153.

7. Chudakov, D. M., Matz, M. V., Lukyanov, S and Lukyanov, K. A. (2010). Fluorescent proteins and their applications in imaging living cells and tissues. Physiol. Rev., 90: 1103-63.

8. DeBaun, R. M and de Stevens, G. (1951). On the mechanism of enzyme action. XLIV. Codetermination of resazurin and resorufin in enzymatic dehydrogenation experiments. Arch. Biochem. Biophys., 31: 300-308.

9. Eliot, M. (1999). Risks of virus transmission associated with animal sera or substitutes and methods of control. Dev. Biol. Stand., 99: 9-16

10. Eshraghi, S and Seifollahi, F. (2003). Antibacterial effects of royal jelly on different strains of bacteria. Iranian. J. Publ. Health, 32: 25-30.

11. Ferlat, S., Bottex-Gauthier, C., Picot, F., Potier, P and Vidal, D. (1994). Study of the immunomodulating properties of 10-hydroxy-2-decenoic acid [10HDA], and its derivatives with glycerol, on a macrophage cell line. Trav. Sci. Cherch. Serv. Sante. Armees., 15: 161-162.

12. Fornwald, J., Lu, Q., Wang, D and Ames, R. (2007). Gene Expression in Mammalian Cells Using BacMam, a Modified Baculovirus System. In (D. W. Murhammer ed) Baculovirus and Insect Cell Expression Protocols, volume 388. New York, Humana Press, pp. 95-114.

13. Fujiwara, S., Imai, J., Fujiwara, M., Yaeshima, T., Kawashima, T and Kobayashi, K. J. (1990). A potent antibacterial protein in royal jelly. Purification 


\section{http://dx.doi.org/10.4314/ajtcam.v11i1.23}

and determination of the primary structure of royalisin. Biol. Chem., 265: 11333-11337.

14. Gerlier, D and Thomasset, N. (1986). Use of MTT colorimetric assay to measure cell activation. J. Immunol. Methods., 94: 57-63.

15. Gstraunthaler, G. (2003). Alternatives to the use of fetal bovine serum: Serum-free cell culture. ALTEX., 20: $275-281$.

16. Haraguchi, T. (2002). Live cell imaging: Approaches for studying protein dynamics in living cells. Cell Struct. Funct., $27: 333-334$.

17. Hinchcliffe, E. H. (2005). Using long-term time-lapse imaging of mammalian cell cycle progression for laboratory instruction and analysis. Cell. Biol. Educ., 4: 284-290.

18. Howe, S. E., Dimick, P. S and Benton, A. W. J. (1985). Composition of freshly harvested and commercial royal jelly. Apic. Res., 24: 52-61.

19. Kamakura, M., Fukuda, T., Fukushima, M and Yonekura, M. (2001). Storage-dependent degradation of 57-kDa protein in royal jelly: A possible marker for freshness. Biosci. Biotechnol. Biochem., 65: 277-284.

20. Kamakura, M. (2002). Signal transduction mechanism leading to enhanced proliferation of primary cultured adult rat hepatocytes treated with royal jelly 57-kDa protein. J. Biochem., 132: 911-919.

21. Kannan, T. P., Ali, A. Q., Abdullah, S. F and Ahmad, A. (2009). Evaluation of Tualang honey as a supplement to fetal bovine serum in cell culture. Food. Chem. Toxicol., 47: 1696-1702.

22. Larson, E. M., Doughman, D. J., Gregerson, D. S and Obritsch, W. F. (1997). A new, simple, nonradioactive, nontoxic in vitro assay to monitor corneal endothelial cell viability. Invest. Ophth. Vis. Sci., 38: 1929-1933.

23. Lemons, J. M., Feng, X. J., Bennett, B. D., Legesse-Miller, A., Johnson, E. L., Raitman, I., Pollina, E. A., Rabitz, H. A., Rabinowitz, J. D and Coller, H. A. (2010). Quiescent fibroblasts exhibit high metabolic activity. PLoS. Biology., 8: e1000514.

24. Lippincott-Schwartz, J., Snapp, E and Kenworthy, A. (2001). Studying protein dynamics in living cells. Nat. Rev. Mol. Cell. Biol., 2: 444-456.

25. Lippincott-Schwartz, J and Patterson, G. H. (2003). Development and use of fluorescent protein markers in living cells. Science., 300: 87-91.

26. Mărghitaş, L. A. (2008). Bee products and their main therapeutic. In (L. A. Mărghitaş ed) Bees and Their Products. Bucharest, Ceres Publishing House, pp. 280-378.

27. Mather, J. P and Roberts, P. E. (1998). Introduction to Cell and Tissue Culture: Theory and Technique. New York, Plenum Press.

28. Mosmann, T. (1983). Rapid colorimetric assay for cellular growth and survival: Application to proliferation and cytotoxicity assays. J. Immunol. Methods, 65: 55-63.

29. Nagai, T and Inoue R. (2004). Preparation and the functional properties of water extract and alkaline extract of royal jelly. Food. Chem., 84: 181-186.

30. Page, B., Page, M and Noel, C. (1993). A new fluorometric assay for cytotoxicity measurements in vitro. Int. J. Oncol., 30: $473-476$.

31. Rieder, C and Khodjakov, A. (2003). Mitosis through the microscope: Advances in seeing inside live dividing cells. Science., $300: 91-96$.

32. Rusan, N. M., Fagerstrom, C. J., Yvon, A-M and Wadsworth, P. (2001). Cell cycle-dependent changes in microtubule dynamics in living cells expressing green fluorescent protein-alpha tubulin. Mol. Biol. Cell., 12: 971-980.

33. Sabatini, A. G., Marcazzan, G., Caboni, M. F., Bogdanov, S and Almeida-Muradian L. B. (2009). Quality and standardisation of royal jelly. JAAS., 1: 16.

34. Salazar-Olivo, L. A and Paz-González, V. (2005). Screening of biological activities present in honeybee (Apis mellifera) royal jelly. Toxicol. In Vitro., 19: 645-651.

35. Schneider, E. L., Braunschweiger, K and Mitsui, Y. (1978). The effect of serum batch on the in vitro lifespans of cell cultures derived from old and young human donors. Exp. Cell. Res., 115: 47-52.

36. Shah G. (1999). Why do we still use serum in the production of biopharmaceuticals? Dev. Biol. Stand., 99: 17-22.

37. Strait, K. A., Warnick, C. T., Ford, C. D, Dabbas, B., Hammond, E. H and Ilstrup, S. J. (2005). Histone deacetylase inhibitors induce G2-checkpoint arrest and apoptosis in cisplatinum-resistant ovarian cancer cells associated with overexpression of the Bcl-2-related protein Bad. Mol. Cancer. Ther., 4: 603-611.

38. Teisch, J and De Sherbinin, A. (1995). Population doubling time: looking backward. Popul. Today., $23: 3$.

39. Tokunaga, K., Yoshida, C., Suzuki, K., Maruyama, H., Futamura, Y., Araki, Y and Mishima S. (2004). Biol. Pharm. Bull., 27: 189-192.

40. Viuda-Martos, M., Ruiz-Navajas, Y., Fernández-López, J and Pérez-Álvarez JAJ. (2008). Functional properties of honey, propolis, and royal jelly. Food. Sci., 73: R117-24.

41. Voytik-Harbin, S. L., Brightman, A. O., Waisner, B., Lamar, C. H and Badylak, S. F. (1998). Application and evaluation of the alamar blue assay for cell growth and survival of fibroblasts. In Vitro. Cell. Dev. Biol. Anim., 34: 239-246.

42. Vucevic, D., Melliou, E., Vasilijic, S., Gasic, S., Ivanovski, P., Chinou, I and Colic M. (2007). Fatty acids isolated from royal jelly modulate dendritic cell-mediated immune response in vitro. Int. Immunopharmacol., 7: 1211-1220.

43. Wadsworth, P and Khodjakov, A. (2004). E pluribus unum: towards a universal mechanism for spindle assembly. Trends. Cell. Biol., 14: $413-419$.

44. Wang Y. (2001). The mechanism of cytokinesis: Reconsideration and reconciliation. Cell. Struct. Funct., 26: 633-638.

45. Watanabe, K., Shinmoto, H., Kobori, M., Tsushida, T., Shinohara, K., Kanaeda, J and Yonekura, M. (1998). Stimulation of cell growth in the U-937 human myeloid cell line by honey royal jelly protein. Cytotechnology., 26: 23-27.

46. Wessman, S. J and Levings, R. L. (1999). Benefits and risks due to animal serum used in cell culture production. Dev. Biol. Stand., 99: 3-8.

47. Willard, H. H., Merritt, L. L and Dean, J. A. (1965). Instrumental Methods of Analysis, seventh edition, California, Wadsworth Publishing.

48. Wistrom, C and Villeponteau, B. (1990). Long-term growth of diploid human fibroblasts in low serum media. Exp. Gerontol., 25: 97-105.

49. Yatsunami, K., Miwa, S and Echigo, T. (1987). Studies on proteins in royal jelly by SDS-polyacrylamide gel electrophoresis. Bull. Fac. Agric. Tamagawa. Univ., 27: 31-40.

50. Zhang, J., Campbell, R. E., Ting, A. Y and Tsien, R. Y. (2002). Creating new fluorescent probes for cell biology. Nat. Rev. Mol. Cell. Biol., 4: 906-918. 